\title{
DA MOBILIZAÇÃO NO ESPAÇO ÀS TERRITORIALIDADES E DISCURSOS PASSIVOS NOS TERRITÓRIOS: OS CASOS DOS PROJETOS DE ASSENTAMENTOS INDEPENDÊNCIA E VARAME I - PASSIRA-PE
}

\author{
FROM MOBILIZATION IN THE SPACE TO TERRITORIALITIES AND PASSIVE DISCOURSES IN \\ TERRITORIES: THE CASES OF SETTLEMENT PROJECTS INDEPENDENNCIA AND VARAME I - \\ PASSIRA-PE
}

Hugo Arruda de MORAIS 1

Artigo recebido em 30/04/2018 e aceito em 31/07/2018

Palavras-chave: Territorialidades passivas;

Autonomia territorial; Autogestão; Assentamentos; Passira-PE.

Keywords:

Passive territorialities; Territorial autonomy; Self-management; Settlements; Passira-PE.

\section{R E S U M O}

Este artigo possui como objetivo central apresentar, de forma sucinta, os resultados das análises feitas em torno da construção dos assentamentos rurais Independência e Varame I (Passira-PE), a partir de uma reflexão que permeia o processo de inclusão socioterritorial das famílias assentadas, tendo por base as territorialidades ativas e/ou passivas. Nessa perspectiva, as análises mostraram que há entre as famílias assentadas dos PA Independência e Varame I, ações de forte individualização e um crescimento de uma concepção de 'não pertencimento' ao lugar, o que impossibilita o surgimento de estratégias inclusivas com capacidade de inovação e transformação do território. 0 que ocorre de fato é um processo de desmobilização em termos de discursos e da tentativa de novas mobilizações coletivas nos territórios. A metodologia para a elaboração deste texto parte da utilização da técnica da Análise Crítica do Discurso. Apresentamos uma análise dos dados que toma como processo básico a análise voltada à descrição, interpretação e explicação dos discursos. O principal resultado deste artigo foi apresentar que entre as famílias assentadas nos PA Independência e Varame I não há no momento ações e comportamentos capazes de construir novas práticas nos PA, a partir de uma lógica de referência e identidades ligadas ao seu território de trabalho e vida.

\begin{abstract}
A B S T R A C T
This article aims to present, in a succinct way, the results of the analyzes carried out around the construction of the rural settlements Independência and Varame I (Passira$\mathrm{PE}$ ), based on a reflection that permeates the process of socio-territorial inclusion of settled families, based on active and/or passive territorialities. In this perspective, the analyzes showed that there are among the families settled in PA Independência and Varame I, actions of strong individualization and a growth of a conception of 'nonbelonging' to the place, which makes it impossible the emergence of inclusive strategies with capacity for innovation and transformation of the territory. Which occurs indeed is a demobilization process in terms of the discourses and the attempt of new collective mobilizations in the territories. The methodology for the elaboration of this text is based on the use of the Critical Discourse Analysis technique. We present an analysis of the data that has as basic process the analysis focused for description, interpretation and explanation of the discourses. The main result of this article was that among the families settled in PA Independência and Varame I, nowadays, there aren't actions and behaviors sufficient to construct new practices in PA, based on a logic of reference and identities related to their territory of work and life.
\end{abstract}

1 Doutor em Geografia pelo Programa de Pós-graduação em Geografia da Universidade Federal de Pernambuco (PPGEOUFPE), Pesquisador do grupo de pesquisa Movimentos Sociais e Espaço Urbano (MSEU-DCG-CFCHUFPE). E-mail: hugo.geografia@yahoo.com.br. 


\section{INTRODUÇÃO}

0 propósito central deste texto é apresentar, de forma sucinta, os resultados das análises feitas em torno da construção dos assentamentos rurais Independência e Varame I (Passira-PE), a partir de uma reflexão que permeia o processo de inclusão socioterritorial das famílias assentadas, tendo por base as territorialidades ativas e/ou passivas (MORAIS, 2017). Tais análises culminaram em uma seção da tese de doutoramento intitulada: Territórios, territorialidades e discursos em torno dos projetos de assentamentos rurais em Passira-PE: uma análise discursiva do processo de inclusão socioterritorial das famílias assentadas. Esta tese é fruto, também, das atividades realizadas no âmbito de uma das linhas de investigação do grupo de pesquisa Movimentos Sociais e Espaço Urbano (MSEU) do qual o autor faz parte como pesquisador e militante.

Para tal, partimos de uma análise que toma por base a perspectiva das territorialidades discursivas (MORAIS, 2017). Essas são ações e práticas sociais dos sujeitos em torno do processo de uso e apropriação do espaço geográfico, em forma de discurso. Numa relação entre grupos humanos e seu ambiente, por meio da linguagem. As territorialidades discursivas podem ser definidas por meio do a) Discurso Ativo ou Positivo que é uma manifestação da linguagem sobre o espaço e que apresenta em sua constituição marcas que caracterizem ações e comportamentos ativos dos sujeitos coletivos no processo de uso, apropriação e construção do território; e do b) Discurso Passivo ou Negativo que seria uma manifestação da linguagem sobre o espaço e não que apresenta em sua constituição marcas que caracterizem ações e comportamentos ativos dos sujeitos coletivos no processo de uso, apropriação e construção do território (MORAIS, 2017).

Nessa perspectiva, as territorialidades nas formas de discursos podem ser definidas como agir social dos sujeitos no seu meio ambiente, sendo vistas em duas dimensões: 1. Como novas formas de mediação, relação e cognição dos sujeitos; 2. Possibilidade de construção de um novo território. Ao mesmo tempo, as territorialidades conduzem: a) Autogestão/Autogoverno/Autonomia - o sujeito é visto com capacidade de construir seu próprio território; b) Consciência de lugar - concepção de pertencimento ao lugar (MORAIS, 2017).

Com isso, as análises nas seções abaixo mostraram que há entre as famílias assentadas dos PA Independência e Varame I ações de forte individualização e um crescimento de uma concepção de não pertencimento ao lugar, o que impossibilita o surgimento de estratégias inclusivas com capacidade de inovação e transformação do território. Entendemos que, após a conquista do território dos PA pelas famílias assentadas, há um processo de desmobilização em termos de discursos e da tentativa de novas mobilizações coletivas nos territórios. A capacidade de "autogestão" que conduziria a uma "consciência de lugar" (reconhecer, ser pertencente e participativo do lugar) e de "autogoverno" (capacidade do sujeito local ser promotor e agir no território a partir da cooperação e da atuação 
conjunta) é diminuída, levando esses sujeitos há um forte "descrédito com o lugar" (MAGNAGHI, 2010).

Nessa perspectiva, a redação abaixo mostra se entre as famílias assentadas nos PA Independência e Varame I há ações e comportamentos capazes de construir novas práticas nos PA, a partir de uma lógica de referência e identidades ligadas ao seu território de trabalho e vida. Objetivamos explicar, por meio desses discursos, se os sujeitos são portadores de consciências de sua participação no processo de construção do território, colocando-os como participantes ativos. Principalmente, após a conquista desse território, fase que se caracteriza por fortes individualizações e um crescimento de concepções de não pertencimento ao lugar, o que impossibilita o surgimento de estratégias inclusivas com capacidade de inovação e transformação do território após a luta pela conquista da terra dos PA.

Para tal, a estrutura do texto foi elaborada de maneira a, primeiramente, colocar os discursos que mostram o não protagonismo nos territórios dos PA entre as famílias assentadas (primeira seção); depois, faremos um exposição e análise dos discursos em torno da não apropriação dos territórios dos PA e da crescente falta de autonomia dessas famílias (segunda seção); em seguida, mostraremos os discursos que deixam claro o forte descrédito com o lugar, ou seja, a falta de interesse e não aceitação dos territórios dos assentamentos como espaços coletivos (terceira seção); e, por último, tecer alguns comentários finais que serviram de encerramento do artigo (parte final) (última seção).

Do ponto de vista do método da construção do escrito ora apresentado, utilizamos a técnica da Análise Crítica do Discurso. Usando tal técnica, apresentamos uma análise dos dados que toma como processo básico a análise voltada à descrição, interpretação e explicação dos discursos (MORAIS, 2017). Para isso, entendemos que a Descrição do Texto é o processo de materialização dos discursos levantados em campo, destacando-se a descrição das palavras/frases/expressões que mantenham relação com o território dos PA; a Interpretação é a etapa de buscar os significados das palavras/frases/expressões com o processo de construção e apropriação dos territórios dos PA; e a Explicação como etapa que mostra o discurso como uma prática socioterritorial, ou seja, o que é dito pelos assentados na relação entre espaço-território-discurso, destacando se há entre esses discursos territorialidades ativas e passivas.

\section{O NÃO PROTAGONISMO NOS TERRITÓRIOS DOS PA}

O processo de ocupações das fazendas Independência e Varame I se deu com forte mediação do MST. Apoio que possibilitou a construção de uma imagem por parte das famílias assentadas do movimento como ator central na conquista dos territórios. Por isso, quando questionados com relação 
à importância do movimento sem-terra na conquista da terra, os discursos centram-se na afirmação de que não haveria conquista da terra sem esta mediação. Assim, verbalizam os assentados:

Porque não conseguia! 0 movimento tem que ajudar. A gente só sabe que a terra é irregular depois que o movimento fala. Ele chegou pra noi e falou ${ }^{2}$ (Discurso assentado 1, PA Independência) ${ }^{3}$.

O MST foi! Sem eles não conquista a terra! [Por quê?] Porque não tinha que ter o cabeça? Tem que ter um dirigente pra tomar a frente. A gente ia entrar com a cara toda pra morrer na bala? A gente já tinha entrado uma vez aqui e saimo. Aí, quando entramo de novo, o fazendeiro daqui tava com a casa cheia de pistoleiro aqui. A gente fumo entrar e eles gritando: sobe e rodando a pistola na mão. [...] Como é que a gente ia se não tivesse o movimento na frente? Como é que a gente ia entrar? (Discurso assentado 2, PA Independência).

Se não fosse o movimento, não entrava não! Porque não entrava! É o que eu acabei de dizer, o povo do INCRA é contra os sem-terra. Vamos dizer: Se o governo vê uma fazenda improdutiva e sabe que o pessoal (sem-terra) quer entra quem podia butar a mão em cima era, primeiramente, o Estado. Se não fosse o MST, não tinha ninguém aqui não, meu amigo. (Discurso assentado 3 , PA Independência).

Não! Só com o movimento! (Discurso assentado 4, PA Independência).

Não! Sem movimento nenhum a gente nunca consegue! [Por quê?] Porque fica difícil! Como é que a gente fica sabendo da verdade, de descobrir a verdade, eles (INCRA) com o papel lá escondido? Se não tiver uma pessoa que informe, por onde começa, você sabe ir? (Discurso assentado 5, PA Independência).

Sem o MST eu não conseguia a terra! Porque o MST é valente, ele vai pra luta! E a gente não lutava! Porque a gente não tinha a ordem e eles já tinha a ordem lá de cair na luta. A gente entramo com ele e ganhamo. Mas, a gente sozinho não ganhava não! (Discurso assentado 6, PA Varame I).

Sem o MST não! Era impossível! Não tinha como não! Como o povo vai entrar na fazenda sem o movimento? O povo critica muito o movimento sem-terra dizendo que é um movimento de ladrão, mas não é não! É um movimento de trabalho! (Discurso assentado 7, PA Varame I).

Eu acho que não! Tinha que ter eles! Tinha que ter eles no mei também! 0 movimento é forte pra isso! Tem que ter eles no mei também. Por pouca coisa que eles faça, mas tem que ter eles no mei também. Porque é eles que levam os problema pra Recife, Brasília (Discurso assentado 8, PA Varame I).

O frenteiro foi o MST! Sem o movimento não tem como não. Eu acho que era mai difici. (Discurso assentado 9, PA Varame I).

\footnotetext{
${ }^{2}$ As frases ou palavras destacadas nas falas dos sujeitos assentados compreendem e representam o contexto socioespacial vivenciado , a partir do processo de luta pela terra e da construção e apropriação do território dos PA. Ao tomarmos a descrição como primeira etapa metodológica, pela qual buscamos descrever a(s) palavra(s)/frase(s) que traga(m) significado(s) estabelecido(s) no processo de apropriação e uso de territórios de assentamentos rurais, em Passira-PE. Nossa preocupação é com a relação entre "palavra/frase-significado-território". Ou seja, centramos nossa análise entre discurso e território, por meio da territorialidade. Por isso, focalizamos uma descrição de determinadas palavras/frases/expressões presentes nos discursos que apresentassem sentidos ligados às territorialidades ou, mais especificamente, às ações que conduzam os sujeitos coletivos a novas formas de organização do território, possibilitando relações de dominação e resistência, e formas de saber e utilização dos recursos territoriais por meio da autonomia e do autogoverno.

3 Optou-se pela transcrição das falas das pessoas mantendo sua forma de expressar-se sobre o mundo. Isso porque nossa preocupação não é com o padrão da norma culta, mas com o que é dito sobre a realidade.
} 
O conteúdo e a construção destes discursos vêm confirmar a importância dada ao MST e é com base em tais verbalizações que passamos a entender como se constituíram os discursos - embora passivos dos assentados e a falta de protagonismo nos territórios.

As palavras/frases/expressões destacadas acima mostram claramente a relação entre obtenção do território e ação desencadeada pelo movimento nas ocupações das fazendas Independência e Varame I. Expressões como "Tem que ter", "Tinha que ter eles", "Sem o MST não", "Se não fosse o MST" constatam claramente que o êxito obtido só foi possível a partir da atuação do MST. Não haveria conquista da terra sem esse apoio, daí verbalizações: "Sem o movimento não tem como não", "Sem movimento nenhum a gente nunca consegue", "Sem o MST eu não conseguia a terra", "Se não fosse o movimento, não entrava não", "Só com o movimento", "não conseguia", "não conquista a terra", "O movimento tem que ajudar", "Se não tiver uma pessoa que informe". Ao mesmo tempo, essa construção discursiva é fruto de uma série de experiências e da vivência das famílias envolvidas com o trabalho de base do movimento. Daí por que os discursos foram construídos, em alguns casos, no plural, dando ideia de uma ação coletiva impulsionada pelo movimento: "A gente entramo com ele e ganhamo", "a gente sozinho não ganhava não".

Nessa perspectiva, partimos de uma análise centrada na reflexão de que para as famílias assentadas, o movimento é visto como o personagem principal na luta pela terra, destacando-se como o ator que foi capaz de protestar e potencializar as suas demandas, conforme afirma um assentado: " 0 MST junto com nós procura os nosso direito!" (Discurso assentado 3, PA Independência). Os discursos acima deixam claro que as relações, as influências e as atuações do MST possibilitaram, de fato, a conquista e a entrada das famílias nos territórios dos PA Independência e Varame I. Inclusive, alguns afirmam que sem o movimento não haveria como "saber a verdade" com relação à condição das terras improdutivas na região:

A gente só sabe que a terra é irregular depois que o movimento fala. Ele chegou pra noi e falou (Discurso assentado 1, PA Independência).

Como é que a gente fica sabendo da verdade, de descobrir a verdade, eles (INCRA) com o papel lá escondido? Se não tiver uma pessoa que informe, por onde começa, você sabe ir? (Discurso assentado 5, PA Independência).

Daí, concordamos com Fernandes (1999) quando afirma ser o trabalho de base do MST um princípio organizacional no processo de socialização política do sujeito sem-terra, possibilitando uma nova forma de organização, (re)criando novos meios de resistência em torno da luta pela terra:

0 trabalho de base é uma metodologia de luta popular, que através de um conjunto das atividades: de reuniões e de formação de pequenos grupos, procura-se a participação de todos. Nestes espaços de socialização política pratica-se a experiência de democratização das informações, de conscientização dos principais problemas que afetam a luta. Nesses espaços nascem a organização e resistência, que levam as famílias ao fazimento da luta (FERNANDES, 1999, p. 77). 
Esse trabalho de base do MST é uma forma de fazer com que o camponês passasse da reinvidicação ao estágio do fazer (FERNANDES, 1999). As ocupações permitem a formação de uma nova consciência e leitura da realidade, baseando-se na necessidade de sobrevivência (FERNANDES, 1999), a partir da busca e da conquista do território camponês.

Nessa perspectiva, o desdobramento principal das ocupações no município de Passira foi construir uma experiência e uma forma de saber socioespacial e territorial, fruto de uma ação coletiva das famílias sem-terra junto ao movimento. Foram as ocupações que permitiram as famílias superar a condição de explorado vivenciada anteriormente, servindo de base para a construção de uma nova realidade socioterritorial. Porém, é válido destacar que as mesmas ocupações não permitiram a formação de um processo de conscientização política efetiva que se estendesse também aos territórios dos PA Independência e Varame I.

Entrentanto, essa espacialização da luta pela terra não conduziu as famílias assentadas ao desenvolvimento de práticas de autogestão e liberdade (FELICIANO, 2006) nos territórios. Em outras palavras, a forma como foi conduzido e vivenciado o processo de ocupações não criou a capacidade de dominação e resistência, a partir da experiência de poder e controle territorial. Daí por que toda a verbalização coloca o movimento como destaque e não enfatiza o papel desempenhado pelos próprios camponeses no processo. Tal afirmativa pode ser confirmada em torno dos discursos da seguinte questão: Qual o real papel do MST: é ajudar as famílias a conquistarem a terra ou a conquistar a terra e continuar lutando por outros benefícios junto às famílias? Assim verbalizam:

Quando a gente estava pegando essa terra, eles ajudava mais ainda pra mode a gente ter a terra. Tem o esforço! Depois que a gente pega, eles ajuda muito também. Mas, eles têm que se deslocar pra outras área pra mode assentar outras pessoa que vive em situação difici (Discurso assentado 1, PA Independência).

É ajudar a gente entrar. Só! Aí não! Quando ele deixa tudo assentado, eles parte pra outro. Pra ajudar a outras família. Hoje ele fica só assinando os papel que tem que assinar pra [os projetos] ir pro banco pra receber o dinheiro [recursos] (Discurso assentado 2, PA Independência).

É entrar aqui e acabou-se! Fechou o tempo! E é entrar aqui e não liberar mais nada pra gente! (Discurso assentado 4, PA Independência).

\section{É butar a pessoa na terra (Discurso assentado 5, PA Independência)}

Tivemo essa luta todinha que a gente teve através deles e ganhamo a terra, mas depois eles fica sem força pra fazer mais (Discurso assentado 6, PA Varame I).

É ajudar a gente entrar na terra. Se não for o MST não entra não. Pelo que eu sei, o MST bota o pessoa na terra e pronto (Discurso assentado 7, PA Varame I).

o MST abandonou a gente. Deixou a gente na terra e estamo tocando o barco sozinho (Discurso assentado 8, PA Varame I).

Eles [MST] só ajuda a entrar na terra. O MST já lutou com a gente. Ele apressava o INCRA lá pra assentar as famia, né? O MST já fez a parte dele, colocou nós aqui dentro. Fez a parte dele junto com o INCRA (Discurso assentado 9, PA Varame I). 
As palavras/frases/expressões "a gente ter a terra", "É ajudar a gente entrar", "É entrar aqui e acabou-se", "É butar a pessoa na terra", "Eles [MST] só ajuda a entrar na terra”, "É ajudar a gente entrar na terra", "o MST bota o pessoa na terra e pronto" nos mostram que a luta pela RA, a partir da espacialização e territorialização da luta pela terra, se limitou a conquista e a entrada nos territórios dos PA Independência e Varame I. A participação das famílias no MST se deu centrada (unicamente) com o objetivo de conquista da "terra para trabalho", não havendo o desenvolvimento e a continuidade do processo de socialização política no e a partir dos assentamentos.

Esses destaques deixam claro que houve uma incompreeensão de todo o processo de espacialização e territorialização da luta pela terra, o que leva ao não entendimento do real papel desempenhando pelo movimento e pelos próprios camponeses. Para os assentados, a luta pela RA, simplesmente, foi uma luta fundiária, uma vez que apresentam um discurso centrado na concepção de que a atuação do MST se encerra na conquista do território4. As palavras/frases/expressões como "Deixou a gente na terra", "O MST abandonou a gente”, "Quando ele deixa tudo assentado, eles parte pra outro", "Depois que a gente pega [...] eles têm que se deslocar pra outras área" deixam evidente que o processo de aprendizado com as ocupações não possibilitou novas formas de organização e resistência junto ao movimento. 0 que observamos nas análises é uma série de discursos passivos com relação ao MST, visto que este "já cumpriu o seu papel" e realizou a RA ao ajudar as famílias entrarem nos PA.

Tais afirmativas podem ser confirmadas com clareza nos discursos de alguns assentados, quando estes falam das ações empreendidas pelo MST em torno das ocupações. Porém, agora, na posição de camponeses com-terra:

\begin{abstract}
A gente aqui não pode sair daqui e ajudar a ocupar fazenda ali não!] [Quais as razões?] Porque eu sou um assentado! E se eu sou um assentado e tu não é, tu é que corra atrás de teus objetivos! Eu não! Eu sou assentado! Nos aqui não pode sair daqui pra ir ali em outra fazenda pra ocupar. O MST quer tirar nos daqui e levar pra ocupar outras fazenda. Agora, o MST pra reforçar o grupo, quer chegar nos assentamento e deslocar a gente, pra gente se arriscar lá na bala na terra do fazendeiro. Isso já tendo a terra conquistada (Discurso assentado 4, PA Independência).

Agora, se eu sair daqui e for fazer outra ocupação, eu não posso entrar em outro assentamento. Meu nome não tá no INCRA porque eu já sou assentado?! (Discurso assentado 7, PA Varame I).

Pelo gosto do movimento, a gente até ia pra ocupação. Mai eu não vou arriscar sair daqui. Agora, depois que tá assentado não pode mai ocupar terra. Pelo gosto do movimento ia, mai eu acho que vai quem quer agora porque o cara não vai deixar o que é dele pra arriscar a vida em ocupação (Discurso assentado 9, PA Varame I).
\end{abstract}

As palavras/frases/expressões "eu sou assentado" deixa claro que com as conquistas dos territórios dos PA, a continuidade de uma consciência coletiva entre esses sujeitos não foi mais

\footnotetext{
${ }^{4}$ Em seu estudo, Martins (2004) já faz essa crítica ao MST.
} 
possível. As construções verbais alicerçam uma perspectiva de ações territoriais que não permitiram a efetivação de uma "identidade territorial local" entre os assentados. Antes, formou-se uma "identidade precária e transitória" (MARTINS, 2004), fortalecida, unicamente, no período das ocupações, e que hoje é incapaz de permitir novas trocas de experiências e ampliação das lutas e de novas conquistas. Nesse caso, toda a construção discursiva faz com que o território não seja visto e nem edificado a partir de ações conjuntas. Daí, discursos com os seguintes conteúdos: “Eu já não conquistei a minha?! Tu corre e vai conquistar a tua, cara!" (Discurso assentado 4, PA Independência); "E se eu sou um assentado e tu não é, tu é que corra atrás de teus objetivos! Eu não! Eu sou assentado!" (Discurso assentado 4, PA Independência); "o cara não vai deixar o que é dele pra arriscar a vida em ocupação" (Discurso assentado 9, PA Varame I).

Essas construções verbais além de reforçar a efetivação dos discursos passivos entre os assentados e o MST, por meio da incompreensão da luta pela terra e pela RA, ainda nos apresentam uma reflexão centrada na existência de territorialidades que não efetivam novas experiências coletivas. Por isso, os assentados hoje são, unicamente, ocupantes dos seus territórios, uma vez que não buscam ações conjuntas e não se colocam como capazes de serem participativos no processo de construção e ampliação das conquistas desses PA. Antes, apresentam-se com posturas individulistas.

Centradas em suas parcelas, as famílias não se veem e se colocam como sujeitos que podem atuar de forma mais efetiva, a partir de ações que possibilitem processos de mudanças e mantendo práticas autonômas, no sentido do controle do lugar (GOVERNA, 2005). Ou com práticas de autogestão, voltadas à construção de projetos coletivos (MAGNAGHI, 2010). Por isso, as atuais territorialidades em torno dos PA Independência e Varame I passam a ser passivas, principalmente, por depender do MST para novas conquistas.

E nessa perspectiva, mais uma vez concordamos com Martins (2003, 2004), quando este afirma que a mediação realizada pelo MST não é capaz de emancipar o sujeito sem-terra. A tutela empreendida pelo movimento social possilita lutas políticas em torno da conquista da terra, mas não a emancipação do camponês, uma vez que é de "fora para dentro" (MARTINS, 2004). Essa mediação faz com que o sem-terra depois de ser assentado, não efetive um projeto social próprio. Antes, eles tenham a sua imaginação e a criatividade social e política bloqueadas (MARTINS, 2004).

Por isso, quando solicitados a fazer uma comparação entre o acompanhamento que o MST deu no período das ocupações e o atual, as famílias assentadas verbalizam:

Diminiu, e muito! Muito! Faz muito tempo que eles deixaram de vim aqui! (Discurso assentado 2, PA Independência).

o apoio de hoje é muito pequeno. Muito pequeno. Eles têm que continuar ajudando! [...] Eles não correram atrás. (Discurso assentado 3, PA Independência).

No acampamento? Vivia mais com a gente lá! Fazia reunião com a gente e prometia aquilo e aquilo outro e nada foi realizado! [...] Ninguém vem aqui não! Eu não conheço nem esse povo mais! [...] Nesse caso, eles abandou a gente! Porque, nesse caso, era 
pra ajudar a gente. A gente espera o dinheiro. Pra que eles liberem o dinheiro pra que a gente melhore (Discurso assentado 4, PA Independência).

Hoje eles não dão ajuda não! Hoje não ajuda não! Eles ajudava naquele tempo de conquistar a terra! Era assim: se a gente precisasse, eles ajudava [...] De vez em quando, eles passam, passa uma equipe e faz uma reunião. Conta umas conversa e a gente fica escutando, mas não chega em nada! (Discurso assentado 6, PA Varame I).

Depois que a gente entrou aqui, eles [MST] não deu feira e assistência a gente mais não. Depois que o cabra entrou aqui pra morar, se vire! Agora, quando a gente tá na lona mesmo ele dá assistência. Eles dava uma feira básica (Discurso assentado 7, PA Varame I).

No começo, eles tava com nós aqui. No começo tinha reunião, eles vinha e conversava. Eles não vêm aqui mais não! Eles esqueceu de nói! Dificilmente vem! (Discurso assentado 8, PA Varame I).

Eles vinha e a gente tava nos barraco e eles fazia as reunião. E mandava a gente não sair. Hoje, eles nunca mai vieram por aqui não [...] 0 que ele [MST] ajudou foi no começo. Quando a gente tava viajando e lutando pela terra. Eles [INCRA] fazia reunião com o chefe do movimento pra assentar as famia. Assentou, a gente tá aqui, fez essas casa que a gente tá dentro e a gente tá se rebolando com a força da gente (Discurso assentado 9, PA Varame I).

As palavras/frases/expressões como "Diminiu, e muito!", "Faz muito tempo que eles deixaram de vim aqui!", “Ninguém vem aqui não!", “Dificilmente vem!”, “Hoje, eles nunca mai vieram por aqui não [...]", "Eles não vêm aqui mais não!" conquistaram que a atuação do MST nos territórios dos PA diminuiu bastante. Mas, além disso, essas construções verbais nos apresentam dois momentos da luta pela terra: um primeiro, no período das ocupações, em que havia forte atuação e presença combativa do movimento sem-terra em defesa das famílias; e um segundo momento, depois da conquista dos territórios dos PA, no qual o MST se "afasta" dos territórios e deixa as famílias sozinhas na condução do processo. Daí a presença de palavras/frases/expressões com as seguintes afirmações: "Eles ajudava naquele tempo de conquistar a terra!", “Agora, quando a gente tá na lona mesmo ele dá assistência”, “0 que ele [MST] ajudou foi no começo. Quando a gente tava viajando e lutando pela terra", "No acampamento? Vivia mais com a gente lá!”, “O apoio de hoje é muito pequeno”, "Hoje eles não dão ajuda não! Hoje não ajuda não!”, “Depois que o cabra entrou aqui pra morar, se vire!”.

Aparentemente, o afastamento pode ser visto como uma saída para a efetivação de uma nova postura das famílias nos PA Independência e Varame I. Estas podem por meio de ações coletivas construir caminhos e alternativas de inclusão já vivenciadas nas ocupações e que poderiam ser ampliadas nos territórios conquistados. Porém, os mesmos discursos apresentam palavras/frases/expressões que confirmam uma forte dependência dos assentados com relação ao movimento e, consequentemente, uma incapacidade em termos de construção de ações coletivas e efetivas nesses territórios. Basta olharmos para as seguintes construções verbais: "Eles têm que continuar ajudando!”, “era pra ajudar a gente”, “Nesse caso, eles abandou a gente!”, “Eles esqueceu de nói!". 
Tais verbalizações nos levam à seguinte interpretação: sem a "ajuda" do MST os problemas enfrentados hoje pelos assentados dificilmente serão superados, principalmente, devido a pouca "atenção" e "ajuda" dada pelo movimento nos PA. Inclusive, alguns assentados, em seus discursos, afirmam a necessidade de continuar a ajuda da parte do movimento para a existência e ampliação de qualquer melhoria ou ação no sentido de beneficiar o território dos PA:

E no momento que o MST faz aquela ocupação e aquela pressão, noi depende de quem? Do movimento [...] 0 movimento tem que ajudar! Mas, como já tem a pressão do movimento em cima dele, aí ele se apressa (Discurso assentado 1, PA Independência).

Se o movimento esquecer da gente e não fizer nada, como é que vai sair o dinheiro e qualquer coisa pra gente? (Discurso assentado 2, PA Independência).

Eles [MST] cobra muita coisa da saúde, educação. Tudo isso eles cobra dentro do assentamento. Na hora que é pra resolver qualquer problema, o movimento quando quer resolver, ajunta todos os agricultores e procura tentar resolver. (Discurso assentado 5, PA Independência).

Depois que a gente ganhou a terra, eles querem ajudar com projeto, só que o projeto não vem! (Discurso assentado 6, PA Varame I).

Nói gostaria que eles estivesse com nói. Era melhor que eles estivesse com nói aqui, dando uma mão, uma força (Discurso assentado 9, PA Varame I).

As palavras/frases/expressões "O movimento tem que ajudar", "Se o movimento esquecer da gente", "Eles [MST] cobra muita coisa", "o movimento quando quer resolver, ajunta todos os agricultores e procura tentar resolver", "Depois que a gente ganhou a terra, eles querem ajudar com projeto" mostram a necessidade de atuação do MST para a ampliação das conquistas nos territórios. Nesse sentido, não há a constituição de sujeitos autonômos e com ações territorilizadas que possibilitem a construção de um novo projeto de território: "noi depende de quem? Do movimento", "Nói gostaria que eles estivesse com nói”, "Era melhor que eles estivesse com nói aqui, dando uma mão, uma força".

Como já afirmamos, os discursos construídos nos PA deixam bem claro que os valores da luta pela terra foram esquecidos ou não foram bem compreendidos, fazendo com que o vocabulário da luta não coincida com o vocabulário da vida (MARTINS, 2004), o que impede o reconhecimento dos sujeitos como protagonistas dos seus territórios, ao mesmo tempo que sua capacidade de ação seja limitada à parcela familiar. Nisso, observamos os PA tornando-se pequenos territórios destinados ao "protagonismo da pobreza" e da precária inclusão (MARTINS, 2004). Assim, reconhece um assentado ao relatar a sua condição de vida e de alguns outros no PA Independência:

Estamos aqui se aguentando a míngua! Tem muita gente morrendo de fome! Eu não morro de fome porque a famia ajuda! Se for pra sobreviver daqui? Eu já tinha morrido! [...] Eu na idade que eu tô, sem entrar nenhum recurso e ainda pra manter meus animal pra ir a frente. Tem dia que eu não tenho nem dinheiro pra comprar um saco de ração pra dá a eles. Eu não posso manter nem uma criação de galinha. Eu vou manter só com a ajuda da famia? Eu tenho que me manter só [...] Noi aqui não 
tem nada favorávi! Tudo aqui é difici! E cada vez mais a gente vai se enterrando. Não temos com quer viver (Discurso assentado 4, PA Independência).

Com isso, não há entre os assentados uma apropriação concreta e simbólica do território, o que leva a uma falta de autoprojeção e representação nos PA, dificultando o seu próprio protagonismo; fato analisado na próxima seção.

\section{A NÃO APROPRIAÇÃO DOS TERRITÓRIOS DOS PA E A FALTA DE AUTONOMIA}

Referenciados em Governa (2005), entendemos que o território é uma construção social que se dá por meio de um conjunto de ações coletivas, pelos quais as territorialidades se constituem em componentes para se entender/compreender como a sociedade se organiza, principalmente, a partir do local de vida dos sujeitos: "[...] l'azione collettiva dei soggetti si costruisce in relazione ai, e in funzione dei, rapporti con il territorio in cui i diversi soggetti agiscono" (GOVERNA, 2005, p. 54).

Nessa perspectiva, o sujeito local é visto como um agente transformador, apresentando capacidades de dominação, resistência e controle do espaço. Isso faz do território um espaço delimitado e construído não somente por forças externas ao lugar, mas, principalmente, pela ação coletiva dos indivíduos na formação de suas identidades: “[...] è una risposta sociale da costrire attraverso l'azione collettiva dei soggetti, una possibile strategia attraverso cui il livello locale definisce il proprio ruolo e la propria identità nel processo di ridefinizione dei livelli terrioriali [...]" (GOVERNA, 2005, p. 54).

Isso faz do território local um espaço de interação, não só física, mas também de dimensões simbólicas, de valores, interesses e de comportamentos (GOVERNA, 2005), em que os sujeitos encontram (ou deveriam encontrar!) sua lógica de referência: “[...] l'identità territoriali si costruisce nell'azione collettiva dei soggeti locali" (GOVERNA, 2005, p. 55). Ao mesmo tempo em que é um produto que se estabelece na mobilização de grupos e de interações de várias formas: no confronto, na cooperação e no conflito (GOVERNA, 2005).

A perspectiva apontada acima é fundamental em nossas análises, uma vez que entendemos que não há entre os assentados uma apropriação concreta e, principalmente, simbólica dos territórios dos PA, no sentido de uma construção coletiva, o que impossibilitando expressões de poder e controle das porções do espaço, a partir de territorialidades ativas (GOVERNA, 2005). Observamos, na realidade estudada, um conjunto de territorialidades passivas que não valorizam os recursos e as pessoas no espaço, constituindo-se com total falta de autonomia e, consequentemente, com uma incapacidade de autorepresentação e autoprojeção (GOVERNA, 2005).

Levantamos essas afirmativas partindo dos discursos construídos a partir da seguinte indagação: A quem pertence esse assentamento: às famílias assentadas, ao INCRA ou ao movimento social?. Assim, verbalizaram os assentados: 
Aqui pertence ao INCRA e ao Movimento (Discurso assentado 1, PA Independência).

Aqui é do INCRA! É do INCRA. O certo, é do INCRA! É do INCRA e junto com o MST. Porque não foi o MST que tomou de conta. Mas, é mais do INCRA! A gente não é dono dessa terra, a gente aqui é preso! (Discurso assentado 2, PA Independência).

É do INCRA! [...] A gente tem documento comprovando que somo assentado. Mas comprovando usucapião não tem]. [...] Eu tenho uns papel aí que comprava que nos somo assentado, que a terra é nossa e tal [...] [Essa terra não é sua?] Comprovado não! Eu tenho como provar que sou assentado! Dono (da terra), não! (Discurso assentado 3, PA Independência).

Isso é do INCRA! Porque aqui a gente pegou uma quadra de terra, que nem eu ganhei onze quadro de terra lá naquela chã. E aquela ali é do IBAMA. (Discurso assentado 4, PA Independência).

É do INCRA! A gente faz um cadastro no nome da gente, comprovando a gente, mas o que o pessoal do INCRA fala é que é sempre deles. Eles (INCRA) fala sempre que é da gente. Pra gente trabalhar! E passar de pai pra filho, de filho pra neto. [Agora, com o tempo, eu acho que a gente temo o direito de abrir a boca e dizer que é nosso. E com o tempo, Eles [INCRA vai dizer que é nosso]. Mas eu acho que eles [INCRA] seja o administradores das coisas. Sempre a gente não pode passar por cima de uma palavra do pessoal do INCRA. Sempre tem que ter uma ordem de respeito de quando eles [INCRA] chegarem, a gente atender bem (Discurso assentado 5, PA Independência).

Quem comanda é o INCRA. A gente tá aqui pro comando do INCRA! O MST colocou a gente, mas a força maior aqui é do INCRA (Discurso assentado 6, PA Varame I).

A terra aqui é do INCRA. A gente é só assentado. Aí com o tempo vem a escritura, vem a emissão de posse. Agora, pra dizer assim, essa terra é sua definitiva, não. Aqui é tudo do INCRA. Eu tenho o RB e administro a terra. (Discurso assentado 7, PA Varame I).

Eu acho que é do INCRA. Agora, parece que depois de dez ano, passa a ser nossa. Ainda não, só quando tiver liberada e ficar pagando a eles (Discurso assentado 8, PA Varame I).

Essa terra não é da gente. A gente tá como cadastrado no INCRA [...] Agora, documento ele não passou ainda. [Você não é o dono da terra?] Eu sou dono porque tô dentro. [...] Mas, se eu tiver aqui dentro trabalhando e movimentando eu tô como dono. Ele diz que eu tô como dono, todos os assentados. Tá dentro da terra trabalhando e morando tá como dono. Embora até aqui não saiu um investimento, não saiu nada (Discurso assentado 9, PA Varame I).

O conteúdo e a construção desses discursos confirmam que a conquista dos PA Independência e Varame I, após a espacialização da luta pela terra, não desencadeou nos camponeses o sentimento de apropriação territorial. As palavras/frases/expressões "Aqui é do INCRA! É do INCRA", "O certo, é do INCRA", "É do INCRA", "Isso é do INCRA", "Aqui é tudo do INCRA", "Eu acho que é do INCRA", "A terra aqui é do INCRA" reafirmam a incapacidade dos assentados em tomarem para si próprios os territórios dos PA. Eles não se veem pertecentes, proprietários e/ou construtores. Ao verbalizarem palavras/frases/expressões como "Aqui pertence ao INCRA e ao Movimento", "É do INCRA e junto com o MST", "mas o que o pessoal do INCRA fala é que é sempre deles" esses sujeitos não reconhecem a sua 
capacidade de atuação, controle e dominação dessa porção espacial. 0 que mostra a sua dependência com relação ao apoio do MST para a ampliação e novas conquistas.

Ao mesmo tempo, as palavras/frases/expressões "A gente tem documento comprovando que somo assentado", "Eu tenho uns papel aí que comprava que nós somo assentado", "Eu tenho como provar que sou assentado! Dono (da terra), não!", “A gente é só assentado. Aí com o tempo vem a escritura, vem a emissão de posse" mostram a incapacidade de autorepresentação e autoprojeção territorial. Ser assentado não significa uma conquista que possibilita a posse e controle efetivo do território de um PA. Mas, é uma condição cedida e condicionada a partir de um documento que permite a ocupação daquele espaço: "Essa terra não é da gente. A gente tá como cadastrado no INCRA", “[...] Eu tenho o RB e administro a terra". A posse efetiva e de direito não existe antes da concessão do INCRA, tornando-os meros ocupantes (sem controle e autonomia): "Quem comanda é o INCRA. A gente tá aqui pro comando do INCRA!", "força maior aqui é do INCRA", "eu acho que eles [INCRA] seja os administradores das coisas”, “[...] com o tempo, eles [INCRA] vai dizer que é nosso”.

É importante deixar claro que no entendimento do camponês sem uma documentação de título de posse da parcela do PA, ele não é o proprietário efetivo do território, conforme deixa claro um assentado: Comprovado não! Eu tenho como provar que sou assentado! Dono (da terra), não! (Discurso assentado 3, PA Independência). Porém, é válido destacar (mais uma vez) que o território é uma realidade material e, ao mesmo tempo, imaterial, fruto de relações de poder e de ações coletivas (RAFFESTIN, 1993; GOVERNA, 2005). E que as práticas dos sujeitos no processo de construção de uma realidade espacial e territorial podem (e devem) ser pautadas por dimensões que vão além da materialidade.

Nesse caso, entendemos que não houve por parte dos assentados uma compreensão do processo em que se encontrava envolvido antes da constituição dos territórios. Conforme já assinalamos na seção anterior, as interações e toda mediação feita pelo MST nas ocupações de terra no município de Passira não proporcionaram entre os indivíduos uma forma de conhecimento e saber que possibilitassem novos caminhos a serem tomados e colocados em prática nos territórios dos PA logo após a sua efetivação enquanto materialidade.

Não há nesses discursos a presença de palavras/frases/expressões que mostrem o entendimento do assentado para o fato de ser o território uma construção alicerçada na dimensão simbólica da realidade e na sua capacidade de atuação. 0 território não é visto e vivido como um palco de relações coletivas e construídas no cotidiano (SANTOS, 2008). Como também, não é percebido e concebido a partir da capacidade de mobilização comum e com forte identidade de lugar (GOVERNA, 2005). Daí o fato do assentado afirmar não ser "dono" e não ter o real controle e/ou domínio sobre o território: "Eu tenho a liberdade de fazer o que quero aqui dentro [parcela]. Agora, muitas coisas 
dependem do INCRA" (Discurso assentado 1, PA Independência). Por isso, o território é visto unicamente como uma materialidade limitada à porção da parcela familiar cedida ou dada pelo INCRA.

A incapacidade do assentado em não se ver como sujeito construtor do seu espaço de vida, reafirma a falta de autonomia no território. Para Governa (2005), a autonomia é a capacidade do sujeito construir o seu próprio território, por meio de expressões de poder e controle no espaço, a partir do "poder dominante". Essa condição é possível através da efetivação de uma identidade territorial coletiva, tornando-se uma forma de dominação e resistência do sujeito no território local: "L'autonomia locale deriva quindi dall'intreccio di relazioni di dominazione e di strategie e tattiche di resistenza" (GOVERNA, 2005, p. 58).

Nessa perspectiva, a autonomia se estabelece no território quando o sujeito cria modalidades e alternativas, dominação e resistência ao que se apresenta enquanto realidade, ditando os caminhos de construção do seu território, o que não é visto entre os assentados dos PA. Afirmamos isto, uma vez que, quando questionados sobre a liberdade de fazer o que deseja em seu lote e no PA, assim, verbalizam:

A gente administra a terra. [...] Eu tenho a liberdade de fazer o que quero aqui dentro [parcela]. Agora, muitas coisas depende do INCRA. (Discurso assentado 1, PA Independência).

o cara pode fazer por vontade dele, mas que o INCRA aceite, não! [...] Não! Pode fazer se o homem [INCRA] disser que é pra fazer. Vamos dizer que é uma cocheira se tiver condição de fazer, um barreiro se tiver condição de fazer, uma porcilga pra criar um porco, um curralzinho pra butar uma vaca, aí você pode fazer. Aí, o INCRA não fala. Agora, tendo o dinheiro pra fazer (Discurso assentado 2, PA Varame I).

[...] aqui ninguém tem nada não meu amigo, aqui é do INCRA! Aqui se fala do INCRA! (Discurso assentado 3, PA Independência).

Uma parte fica pra gente criar e trabalhar. Mas, eles [INCRA] dii logo: ninguém pode vender! 0 que é da gente, a gente pode vender, trocar o que quiser. Mas, aqui ninguém pode fazer nada! Uma terra é da gente quando a gente pode fazer o que quer na terra. A gente não pode vender. Vamos vender ela, não pode construir nada em outro lugar (Discurso assentado 4, PA Independência).

Na nossa administração de trabalho (no lote), a gente faz o que quer: corta terra, planta. A adminstração é da gente. Agora, já em ponto de dizer que é "dono-dono" ninguém se acha com esse direito ainda não (Discurso assentado 5, PA Independência).

A gente só pode fazer alguma coisa se o INCRA permitir! O INCRA é o responsável por aqui, mesmo sem vim aqui! Fazer o que, né? Enquanto isso, a gente não pode dizer que a terra é da gente por que tem o INCRA que tá à frente (Discurso assentado 6, PA Varame I).

Aqui não pode fazer casa pra um filho. Só se o INCRA autorizar. [Por que não pode?] Eu não sei! É uma regra que o INCRA tem. Então, essa terra não é minha, né? Tem que trabalhar muito pra essa terra ser minha! Esse terreno passa a ser meu depois de dez ano (Discurso assentado 7, PA Varame I). 
Ninguém pode fazer nada, ninguém pode vender (Discurso assentado 8, PA Varame I).

O INCRA já fei reunião e dii que é do assentado. Agora, se o assentado for embora, fizer um abandono, eles pode até butar outro se deixar abandonado. Agora, enquanto tá dentro morando, e o cara tá produzindo dentro, ou pouco ou muito mai tá produzindo, tá se virando dentro da parcela, e o cara tá se movimentando dentro, eles [INCRA] dii que é do assentado (Discurso assentado 9, PA Varame I).

As palavras/frases/expressões destacadas acima são exemplos de construções discursivas que mostram a falta de autonomia no território por parte das famílias assentadas. Afirmar "O INCRA já fei reunião e dii que é do assentado", "já em ponto de dizer que é "dono-dono", ninguém se acha com esse direito ainda não", "essa terra não é minha, né? Tem que trabalhar muito pra essa terra ser minha!", “[...] aqui ninguém tem nada não meu amigo, aqui é do INCRA!", levam a uma interpretação de que os assentados não tomam posse do PA. Não se colocam como proprietários do território. Esses discursos só confirmam a falta de "poder dominante", ou seja, de controle do PA como um todo. Afirmar que "ninguém tem nada", não se reconhecer "dono" ou que o "INCRA diz" é não se ver como um sujeito pertencente e participativo no lugar. É, no mínimo, não construir práticas coletivas ou processos e relações de poder que possibilitem dominação e exploração, pelo menos, simbólica da realidade.

Daí por que um discurso centrado em palavras/frases/expressões como "O cara pode fazer por vontade dele, mas que o INCRA aceite, não!”, “Pode fazer se o homem [INCRA] disser que é pra fazer”, "Ninguém pode fazer nada", "A gente administra a terra [...] Agora, muitas coisas depende do INCRA", “A gente só pode fazer alguma coisa se o INCRA permitir! O INCRA é o responsável por aqui” mostra que os assentados não criam situações, estratégias e ações que resistam às imposições ou posturas do INCRA dentro dos PA. Essa falta de autonomia e poder dominante não permite o desenvolvimento de territorialidades ativas que conduzam à coscienza di luogo (MAGNAGHI, 2010), colocando-os como sujeitos passivos nos PA Independência e Varame I.

Essa condição de falta de autonomia conduzirá, por conseguinte, a uma persistência de territorialidades passivas entre os assentados. Isso levará à construção de discursos passivos e que trazem um forte processo de individualização e descrédito com relação à perspectiva de pertencimento e da consciência de lugar, aspecto que abordaremos na seção seguinte.

\section{OS TERRITÓRIOS DOS PA E DESCRÉDITO COM A CONSCIÊNCIA DE LUGAR}

Não há entre os assentados do Independência e Varame I uma capacidade de autoprojeção e autorepresentação com os territórios dos PA como um todo. A concepção de um PA comum, coletivo e capaz de levar todos para um novo destino é, no mínimo, esquecida ou mal compreendida no momento. 0 que observamos em campo e nas análises feitas é a forte concepção de ser a parcela 
familiar a porção do espaço dedicado a vida e ao trabalho da família. Assim, verbalizam alguns assentados:

Aqui a bocada não é de brincadeira não! Aqui é pra trabalhar! Aqui não é pra ficar de cara pra cima! Aqui é assim! Se quiser viver, se não quiser! (Discurso assentado 1, PA Independência).

A gente tem que trabalhar. Se não trabalhar ninguém vevi! Como é que você vevi sem trabalhar? Você vevi sem trabalhar? Tudo hoje depende do trabalho! 0 cara só tem as coisas se trabalhar! Tudo você consegue se trabalhar! (Discurso assentado 2, PA Independência).

o que a gente faz aqui é com a força da gente, é com o trabalho da gente (Discurso assentado 9, PA Varame I).

As palavras/frases/expressões destacadas acima mostram claramente a ligação do sujeito com a terra, mas, principalmente, com a parcela de trabalho e moradia dentro dos territórios dos PA. Fato justificado uma vez que os camponeses têm um histórico familiar ligado ao trabalho na agricultura. Porém, é válido destacar que não necessariamente esse elo com a parcela ou lote possibilita uma articulação com projeto de assentamento e os demais assentados.

Após a conquista dos territórios, aumentou a individualidade entre as famílias. Observamos que existe o crescimento da concepção de não pertencimento ao lugar ${ }^{5}$. As formas de atuação dos assentados no Independência e Varame I não permitem a construção de um protagonismo coletivo, como também da existência de uma "coscienza di luogo"6. Isso impossibilitou o desencadeamento de estratégias inclusivas com capacidade de inovação e transformação desses territórios. Ao mesmo tempo em que não estabeleceu uma relação de experiência cotidiana, em que cada assentado passasse a cuidar, participar e valorizar o ambiente coletivo do assentamento.

Essa observação é fundamental nas análises que se seguem uma vez que ao serem questionados com relação à união e à ligação das famílias no período referente às ocupações e no estágio atual, observamos os seguintes discursos:

Sempre se reunia mai uma coisinha! Se reunia! Porque quando começou fazia umas reuniãozinha. Assim, pegava dez, doze homi, ia fazer uma parcela, ia fazer uma picada, ia ajeitar um buraco de ceica. Era o povo baguçando no açude, se ajuntava um moi de homi e ia lá impatar. Porque tava fumando droga pra lá, porque tava quebrando vidro. Era mai unido uma coisinha! Mai depois que cada cá passou pra sua parcela, acabou-se tudo [toda a união]! (Discurso assentado 1, PA Independência).

Quando a gente tá querendo ganhar a terra do assentamento, a gente tá mais unido, a gente vai atrás das coisas, tá tudo junto. Agora, quando a gente ganha a

\footnotetext{
${ }^{5}$ Aqui, com base em Magnaghi (2010), entendemos o território como sendo um lugar histórico e construído a partir de uma identidade territorial, desencadeado por um processo de territorialização que permite um processo de reorganização, transformação e nova dinâmica do e no território. Lugar onde os indivíduos acumulam e depositam seu próprio conhecimento ambiental ("sapienza ambientale").

${ }^{6}$ Magnaghi (2010) entende consciência de lugar como uma conjunto de ações e pensamentos calcados em novas formas de socialização coletiva, permitindo tornar os sujeitos locais como verdadeiros promotores do desenvolvimento (MAGNAGHI, 2010).
} 
terra as pessoas vão correr atrás das coisas dele [da parcela] (Discurso assentado 2, PA Independência).

No período do acampamento! Muito, muito, muito mai! Hoje é mai individual! União aqui é muito pouca! Aqui, quando nós estava tudo ali debaixo da barraca de lona, todo mundo se chamava de companheiro e meu irmão. Era meu irmão e meu companheiro! Na hora que pegaram as terra mudou totalmente meu amigo. Totalmente mudou! É o seguinte: pelo que eu vejo, a maioria do povo que tá aqui comeram os dois fomento, comeram o dinheiro dos carneiros, agora vem esse projeto, e parte para a rua e o mato cobre aí. (Discurso assentado 3, PA Independência).

Aqui é assim: cão comendo cão! Eu moro esse ano todinho aqui e nunca fui na casa de ninguém. Não adianta. Aqui é um fuxicado, uma bagunça (Discurso assentado 4, PA Independência).

Hoje, depois de assentado, o agricultor vai pra sua terra (muitos, não todos) e fica recolhido. Porque corre, corre e não vê nada! Eu acho que eles querem cansar (da luta)! Mas, não pode cansar, tem que correr atrás. (No período do acampamento) Era todo mundo junto, todo mundo batalhava junto. Hoje é cada um por si! [...] Se hoje tem no assentamento cinquenta família, talvez quinze ou vinte corra atrás. 0 resto dii logo: "Eu vou fazer mai o que? A gente corre atrás pra fazer reforma agrária, pra trazer algum recurso aqui pra dentro e só tem mentira!”. Aí fica difícil! (Discurso assentado 5, PA Independência).

[...] hoje em dia, você ganhou, eu ganhei, você vai cuidar do que é seu. [...] Cada cá é no seu! Cada um queria ganhar a sua terra se chama de companheiro, mas agora, cada cá pra si (Discurso assenatdo 6, PA Varame I).

Isso aí é uma questão muito individual. Porque quando dividiu a terra, cada um foi fazer o seu. E pronto. Aqui cada cá é por si. Cada cá cuida do seu. Cada cá faça o seu (Discurso assentado 7, PA Varame I).

Hoje, cada um se preocupa com a sua parcela. Nói toma conta da nossa terra e os outro da sua, das dele (Discurso assentado 8, PA Varame I).

Cada um agora tá preocupado com a sua [parcela]. É desse jeito. Se tem um assentado que não cuida da parcela dele nem no inverno, eu vou cuidar da parcela da gente (Discurso assentado 9, PA Varame I).

O conteúdo e a construção desses discursos vêm mostrar que com a espacialização da luta pela terra houve uma ligação entre os camponeses, a partir de suas imaterialidades existenciais, o que levou cada um a ter um sentimento de pertencimento. As palavras/frases/expressões como "Aqui, quando nós estava tudo ali debaixo da barraca de lona, todo mundo se chamava de companheiro e meu irmão.", "Cada um queria ganhar a sua terra se chama de companheiro", "Quando a gente tá querendo ganhar a terra do assentamento, a gente tá mais unido, a gente vai atrás das coisas, tá tudo junto" reafirmam que as ocupações e os acampamentos representaram espaços de socialização política, tornando-se locais onde a força da atuação coletiva ganhou mais significado e mais intensidade: "Era todo mundo junto, todo mundo batalhava junto". Foram nesses espaços de atuação conjunta que ocorreram as primeiras vitórias e derrotas na luta pela terra, fortalecendo as práticas socioterritoriais, permitindo a formação de espaços solidários, de entrosamento, ao mesmo tempo em que edificaram uma identidade: “Era meu irmão e meu companheiro! 
No momento em que predomina o objetivo inicial - luta pela terra -, forma-se uma forte e dinâmica ligação entre as várias famílias que compõem MST; e isto porque o seu "cordão umbilical", que é aquele objetivo comum, continuava acontecendo: o desejo de conquistar a terra. Porém, quando os assentamentos ocorrem, ou seja, quando a terra é, enfim, conquistada, aquele objetivo é substituído pelo da manutenção da unidade familiar, o que provoca um quase total desligamento de relações entre as famílias assentadas. Conforme observamos nas seguintes palavras/frases/expressões: "Era mai unido uma coisinha! Mai depois que cada cá passou pra sua parcela, acabou-se tudo [toda a união]!”, "Na hora que pegaram as terra, mudou totalmente meu amigo. Totalmente mudou!".

Como já afirmamos, após a conquista do território do assentamento, aumentou-se a individualidade entre os assentados. A mobilização inicial não desencadeou a continuidade de territorialidades ativas nesses territórios. Antes, observamos discursos passivos e ações com forte marca da individualidade e do descrédito com o lugar. Ou seja, da não concepção de pertencimento. Não houve nos territórios dos PA a construção de uma identidade local coletiva e historicamente construídas e influenciadas por processos cognitivos, linguísticos, perceptivos e sensoriais (MAGNAGHI, 2010).

Verificamos essas afirmativas nas seguintes palavras/frases/expressões: "mas agora, cada cá pra si", "Isso aí é uma questão muito individual”, “Aqui cada cá é por si. Cada cá cuida do seu. Cada cá faça o seu”, "União aqui é muito pouca!”, “Hoje é cada um por si”. Essas construções discursivas confirmam a tendência ao individualismo. Expressões pautadas e referenciadas no "cuidar do seu" chamam atenção para o fato da valorização da unidade familiar, ao mesmo tempo em que as ações coletivas são diminuídas.

Por isso, discutir as formas de sociabilidade dentro dos PA Independência e Varame I pode ser cabível, uma vez que se, parte da ideia do assentamento rural como provocador de contato mais concreto entre os assentados. Daí por que concordamos com Leite (2004) quando afirma que o assentamento, em si, reúne parte de uma comunidade ou até mesmo a comunidade inteira. Ou com Feliciano (2006) quando diz que assentar é ordenar certas comunidades 7 . Porém, a conquista da terra ocasionou uma ruptura entre o discurso e a realidade. Como também uma negação do discurso de união e cooperativismo pregados pelo movimento: "Na hora que pegaram as terra, mudou totalmente meu amigo. Totalmente mudou!”. Com a nova condição social, não houve uma maior integração social entre os assentados. 0 cotidiano territorial nos PA não facilitou e nem reafirmou a integração social vivida anteriormente. Agora, a dinâmica diária nesses territórios valoriza a concepção individual em relação à coletiva.

\footnotetext{
${ }^{7}$ A luta pela terra pode se dar a partir da dimensão local/municipal. Os assentados entrevistados não eram pessoas estranhas entre si, tendo havido uma proximidade que se reafirmou nas ocupações e nos acampamentos. Muitos deles passaram a fazer parte do movimento e começaram a ocupar fazendas do município através de convite de conhecidos que já tinham convivido e trocado experiências anteriores e que já faziam parte do movimento social.
} 
Segundo observado em campo e nas entrevistas realizadas, na condição de assentado, muitos beneficiados perdem o contato de vizinhança vivida e fortalecida anteriormente nas ocupações e nos acampamentos. Agora, a maioria passou a relacionar-se ou manter seu principal vínculo com a sua própria família, numa super valorização da unidade doméstica. Como observamos nas seguintes construções discursivas: "Mai depois que cada cá passou pra sua parcela, acabou-se tudo [toda a união]!", “Agora, quando a gente ganha a terra as pessoas vão correr atrás das coisas dele [da parcela]”, "Hoje depois de assentado o agricultor vai pra sua terra (muitos, não todos) e fica recolhido", "você ganhou, eu ganhei, você vai cuidar do que é seu. [...] Cada cá é no seu!”, “Porque quando dividiu a terra, cada um foi fazer o seu", "Hoje, cada um se preocupa com a sua parcela", "Cada um agora tá preocupado com a sua [parcela]". As palavras/frases/expressões acima mostram que a unidade de moradia e trabalho passou a ser o ambiente de sociabilização existente nos PA Independência e Varame I em detrimento dos territórios como um todo, o que levou a quase que total diminuição ou perda do contato entre as famílias envolvidas.

Esse aspecto tem sido demonstrado por vários autores que se debruçaram sobre a questão dos movimentos sociais. Destacamos Carvalho (1998) quando argumentou que há uma tendência ao individualismo entre as famílias assentadas em vários PA no país. Diz o autor que:

[...] nos assentamentos de reforma agrária predomina o comportamento individualista das famílias dos trabalhadores rurais com relação à gestão do assentamento, à forma de apropriação da terra, ao processo produtivo amplo senso, incluindo a comercialização, e às relações com os organismos governamentais mediadores das políticas públicas (CARVALHO, 1998, p.6).

Para Carvalho (1998), essa tendência à valorização do lote familiar é uma forma de tentar consolidar a unidade camponesa como um local de consumo e de produção. 0 que faz necessário prestar bem atenção e continuar vigilante no que concerne às novas situações surgidas, diante das demandas que são desencadeadas pela condição de assentado, o que ele chama de "estabilidade psicossocial" (CARVALHO, 1999) ${ }^{8}$. Desse modo, segundo o autor, pode haver novas formas de interação, tendendo a aumentar as relações estabelecidas entre os parentes da unidade familiar e o lote de sua moradia, diminuindo o contato entre as demais famílias e, consequentemente, a interação social no assentamento.

\footnotetext{
8 Para o autor, as interações dentro do território dos PA são fortemente baseadas em relações em que o lote familiar se constitui na unidade base de interação: "A nova interação social que começa a acontecer no assentamento, mesmo que já tenha sido iniciada na fase do acampamento (quando houver), dá-se predominantemente entre pessoas completamente estranhas e que não tiveram base comum na vida cotidiana. Portanto, essas pessoas estão psicologicamente vulneráveis e o apego ao seu lote e à moradia é reforçado. Dessa forma, ainda que esse comportamento possa ser característico de um período de transição, as famílias tendem a: enfatizar a importância do seu lote e da sua moradia, seja para reiniciar as atividades relacionadas com a produção seja para encontrar o abrigo desejado para si e sua família naquilo que é "seu" (superação do nomadismo geográfico e social); [...] se o processo de constituição do assentamento e de organização da vida social coletiva dá-se com muitas divergências internas a tendência da maioria das famílias é a de reafirmar as identidades sociais anteriores, mesmo que posteriormente essas identidades sociais possam ser significativamente modificadas" (CARVALHO, 1999, p. 16).
} 
Quando questionados, poucos são os assentados que falam nesse assunto. A maioria diz que não sabe ou não deseja falar. Alguns confirmam que boa parte das famílias não tem interesse pelas questões referentes ao assentamento, tanto no que se refere às questões de trabalho nos lotes como aos problemas dos PA. Um aspecto observado em campo e que pode ser considerado aqui, mesmo não sendo apresentado nos discursos levantados, é que as antigas formas de exploração sofridas pelos chefes familiares, através da submissão a trabalhos alugados e ao arrendamento de terras, podem ter um peso muito grande nas atuais formas de socialização existentes dentro dos $\mathrm{PA}^{9}$.

A condição vivida anteriormente deve ser, portanto, um fator relevante já que muitas famílias assentadas hoje não sabiam trabalhar de forma associada, reduzindo, também, o nível de interação entre eles. Nesse caso, a individualidade pode ser fruto, também, de rugosidades inerentes ao passado de exploração. 0 que, por seu turno, influenciam diretamente nos graus de interação nos assentamentos, dificultando o associativismo e a busca de soluções comuns para os problemas dos PA. Também, o baixo nível de escolaridade dos chefes familiares pode ser um outro fator ${ }^{10}$.

O descrédito com relação À consciência de lugar é tão grande que faz com que a associação dos trabalhadores assentados dos PA Independência e Varame I não tenha uma função clara, inexistente em termos práticos. As associações existem "no papel”, porém não têm uma atuação ativa. Entendemos que a existência dessa forma de organização é fruto da própria necessidade imposta pelo Estado,

\footnotetext{
${ }_{9}$ Segundo aponta Fabrini (2002), um dos grandes problemas que limita o aumento de ações mais coletivas nos PA deve-se ao processo histórico de formação de sujeitos não políticos. O processo de exploração sofrida anterior por essas famílias assentadas facilita o agravamento das dificuldades de consolidação das atividades coletivas Assim, afirma o autor: "Um dos obstáculos para o desenvolvimento do trabalho coletivo nos assentamentos, segundo o MST, são as características camponesas dos assentados. Estes não apresentam consciência coletiva formada a partir da divisão do trabalho. 0 entendimento do MST é que no processo de produção camponesa se forma uma consciência corporativa e de aversão às atividades coletivas, diferentemente do que ocorre com a produção capitalista nas indústrias. A coletivização da terra, trabalho, instrumentos, gestão da produção seria uma condição para superação da consciência camponesa dos assentados e conseqüentemente construção da consciência coletiva. [...] A eliminação das características camponesas dos assentados seria uma necessidade, pois são um obstáculo para o desenvolvimento econômico, social, político dos assentados. A própria expansão das lutas, dependeria da superação das características camponesas dos assentados. O MST entende que os camponeses nos assentamentos não possuem "consciência coletiva" por causa da forma como estão inseridos no processo produtivo" (FABRINI, 2002, p. 89). Para Carvalho (1999), os fatores históricos e econômicos nos quais as famílias assentadas tiveram suas origens influenciam diretamente na ligação atual e quase restrita entre os membros da família. Como mostra o autor, os planos sociais e econômicos anteriores ao assentamento influenciam de forma direta na atual forma de organização e vivência dos assentados. As experiências atuais são fruto das formas anteriores dos trabalhadores, determinando comportamentos e influenciando nas novas formas de organização no território "seus pares de forma a potencializar as forças produtivas e os meios de produção disponíveis nos assentamentos".

10 Em pesquisa anterior, foi possível fazer uma entrevista com o coordenador do MST na região do Polo Bom Jardim. Para este assentado e líder do movimento, o problema do individualismo nos PA decorre também do nível de educação e do tipo da formação histórica inerentes às famílias assentadas, sendo estes os dois fatores que mais dificultam a formação e consolidação das práticas coletivas dentro dos PA. Assim, diz: "A gente sempre discutimos e sempre defendemos o coletivo, a coletividade. A gente sabe que juntos a gente forma uma força maior. 0 individual, a gente não consegue chegar a canto nenhum. Só que o trabalhador aqui no Nordeste, não é só em Passira não, não tem essa visão. Os assentamentos no sul é diferente, eles têm uma visão mais coletiva. Por isso, eles se dão melhor do que aqui. [Por que essa questão da individualidade?] A escolaridade é um fator. A maioria não conseguiu completar a oitava série, outros só têm o primário, outros nem o primário, aí a cabeça dele fica: eu quero meu sitiozinho, aquilo ali, individual para ninguém tá butando o bico nem nada. Eles não conseguem enxergar a frente. [...] No acampamento a gente tenta fazer tudo no coletivo, se é para limpar, fazer barraca, tudo a gente faz no coletivo, mas quando chega no assentamento é cada cá eu quero o meu e xau. Tanto é que, quando a gente forma uma associação, a gente discute com eles para eles deixarem uma área coletiva justamente" para que a gente possa fazer projetos para a associação para desenvolver o assentamento como um todo. Porque, sozinho na parcela, eles não vão conseguir, e daqui a dez anos vão estar na decadência. Porque não tem o estudo suficiente para isso e a visão deles é só essa: só ter um sitiozinho" (Discurso, Coordenador regional do MST).
} 
através do INCRA, uma vez que os repasses de créditos e benefícios para as famílias só se dão através desta instituição. Esse fato é bastante significativo nos PA, pois a capacidade dos sujeitos serem promotores ou atores nos territórios se faz reduzida.

Por isso, ao serem questionados sobre o papel da associação dentro dos PA, alguns não queriam falar. Os que se pronunciaram afirmavam desacreditar nessa forma de organização camponesa. Assim, verbalizam:

A associação daqui acabou-se! A gente pagava sempre, todo mei. Mai, acabaram e eu não vi mai ninguém falar nesse negócio de associação. Não tá funcionando não! (Discurso assentado 1, PA Independência).

O papel da associação aqui dentro é quase zero! [Funciona?] Em nada! (Discurso assentado 3, PA Independência).

Associação ninguém ver falar! Fizeram associação aqui. Uns paga outros não paga e acabou (Discurso assentado 4, PA Independência).

Associação sempre corria atrás das coisas, mas sempre é renegado. A gente faz mais o que? (Discurso assentado 5, PA Independência).

A associação não pode ajudar! (Discurso assentado 8, PA Varame I).

[A associação] Vê o problema que tem aqui dentro e levar lá pro INCRA. [...] mas sempre falta um ou outro porque tem as suas ocupações (Discurso assentado 9, PA Varame I).

O conteúdo e a construção desses discursos através de palavras/frases/expressões "acabouse!", “Não tá funcionando", “quase zero!", "ninguém ver falar!”, “não pode ajudar!” mostram a incapacidade dos indivíduos atuarem como agentes ativos. Verbalizar sem saber o que fazer, "A gente faz mais o que?", ou colocar as ocupações do trabalho do lote como principal preocupação, "mas sempre falta um ou outro porque tem as suas ocupações", é negar a capacidade da coletividade em ser construtora de um projeto territorial novo.

Em conversa com os assentados e sem o gravador estar ligado, observamos que as reuniões das associações caracterizam-se como os únicos momentos de contato entre as famílias, constituindose em períodos de discussão e debate intenso. Porém, hoje, são espaços de pequeno interesse. Poucos são os beneficiados que comparecem às reuniões, as quais são marcadas várias vezes.

Apesar de alguns avanços, a inclusão socioterritorial das famílias assentadas ainda se faz precária, sobretudo, no que diz respeito à construção de lugares fortes. Assim, pode-se afirmar que a implantação dos PA ainda não possibilitou o desenvolvimento de uma interação social entre os assentados capaz de desencadear ações efetivas de maior sociabilidade reforçadoras das territorialidades ativas. 


\section{CONSIDERAÇÕES FINAIS}

A investigação permitiu a visualização dos PA Independência e Varame I como territórios que revelam uma dinâmica socioterritorial conflituosa. Com base nos discursos acima analisados, identificamos ações que tem forte passividade diante da realidade territorial vivenciada nos PA, o que leva aos assentados não se verem como verdadeiros protagonistas no processo de construção dos territórios. Os discursos e as práticas socioterritoriais não apresentam uma capacidade de dominação e resistência; ao mesmo tempo, que não se configuram em práticas de cooperação e comportamentos de caráter coletivo e de autoprojeção nos territórios.

A partir dos discursos analisados, observamos claramente a incompreensão por parte dos assentados com relação a seu papel e a sua participação nos novos territórios conquistados "ou recebidos". As famílias assentadas ao não se colocarem como protagonistas apresentam uma visão limitada da realidade. São discursos que mostram a falta de consciência, da força e da capacidade de atuação, mobilização e organização existentes no período das ocupações que não continuaram com a conquista dos territórios dos PA. Isso fez com que o passado recente de ação conjunta na luta pela terra não fosse mais vivenciado e a relação de comunidade deixasse de existir, para se viver relação individualizada entre assentado/Estado/Movimento: Aí, a gente aqui depende do INCRA e depende do MST. Mesmo que o INCRA seja lento, a gente depende dos dois. Só tamo aqui por causa do INCRA e do MST também (Discurso assentado 1, PA Independência).

Por isso, afirmamos que na atual fase, o que observamos são territorialidades passivas entre os assentados no seu acontecer territorial. Os assentados não se veem no território: Aqui pertence ao INCRA e ao Movimento (Discurso assentado 1, PA Independência); Aqui é do INCRA! [...] A gente não é dono dessa terra, a gente aqui é preso! (Discurso assentado 2, PA Independência); É do INCRA! [...] Eu tenho como provar que sou assentado! Dono (da terra), não! (Discurso assentado 3, PA Independência); Isso é do INCRA! (Discurso assentado 4, PA Independência); É do INCRA! (Discurso assentado 5, PA Independência); Quem comanda é o INCRA [...] MST colocou a gente, mas a força maior aqui é do INCRA (Discurso assentado 6, PA Varame I); A terra aqui é do INCRA. A gente é só assentado (Discurso assentado 7, PA Varame I); Eu acho que é do INCRA (Discurso assentado 8, PA Varame I); Essa terra não é da gente. A gente tá como cadastrado no INCRA (Discurso assentado 9, PA Varame I).

Os discursos mostram a incapacidade desses assentados se verem autorepresentados ou autoprojetados. Eles apresentam uma grande dificuldade de dominação, muito menos de apropriação simbólica dos territórios. 0 que faz com que a conquista da terra não seja vista como fruto da ação das famílias camponesas junto com o MST, mas da relação de proximidade e entendimento do movimento com o INCRA: Eu acabei de dizer agora, a terra não era improdutiva. Aí o que é que o INCRA faz? Ele entra em contato com o MST, que é o movimento da Reforma Agrária, e o INCRA repassa para o MST e 
o MST ocupa as fazendas e bota as famílias pra trabalhar (Discurso assentado 1, PA Independência); ou da "boa" atitude e vontade do INCRA para com as famílias que participaram do movimento: [...] mim dá um cisterna, foi mim dá uma casa, foi oficializar a minha terra [...] Isso o INCRA deu a mim. [...] (Discurso assentado 3, PA Independência). Daí a submissão diante do órgão estatal: [...] a gente não pode passar por cima de uma palavra do pessoal do INCRA. Sempre tem que ter uma ordem de respeito de quando eles (INCRA) chegarem, a gente atender bem (Discurso assentado 5, PA Independência).

Essa não apropriação concreta e simbólica do território caracterizada pela total falta de autonomia e capacidade efetiva de governança mostra que há entre os assentados o crescimento das ações de forte individualização. Eles não se veem pertencentes ao lugar, os territórios não são coletivos: Aqui tem união de nada na vida! (Discurso assentado 2, PA Independência); Hoje é mai individual! (Discurso assentado 3, PA Independência); Se hoje tem no assentamento cinquenta família, talvez quinze ou vinte corra atrás (Discurso assentado 5, PA Independência); Cada um quer cuidar do que é seu. Não dá mais a mão pra ajudar no que é dos outro (Discurso assentado 6, PA Varame I); É desse jeito. Se tem um assentado que não cuida da parcela dele nem no inverno, eu vou cuidar da minha parcela (Discurso assentado 9, PA Varame I).

Essas posturas impossibilitam o surgimento de estratégias inclusivas e com capacidade de inovação e transformação do território. 0 que demonstra tendências ao individualismo, existentes no interior dos PA, colocando os assentados dentro do isolamento, tanto com relação aos seus próprios companheiros como aos demais atores sociais. Preocupados unicamente com a manutenção da unidade familiar, os assentados do PA Independência e Varame I enfrentam uma série de dificuldades ou barreiras ao rompimento com os laços tradicionais da agricultura local. A tendência ao individualismo impossibilita a formação de associações ou cooperativas que organizem e dinamizem a produção agrícola nos PA. 0 que, consequentemente, leva à perpetuação da cultura da espera: Eu vou fazer mai o que? A gente corre atrás pra fazer reforma agrária, pra trazer algum recurso aqui pra dentro e só tem mentira! Aí fica difícil! (Discurso assentado 5, PA Independência). Porque, se fosse pelos movimento, as coisa era outra. Se fosse administrado tudo por ele. (Discurso assentado 6, PA Independência). A incapacidade de manterem-se unidos e de buscar a construção coletiva do território faz com que os assentados aceitem de forma "natural" as dificuldades nas quais esbarram cotidianamente: Mas aqui é assim, parado, no tempo de Deus! Pronto, viver assim! (Discurso assentado 3, PA Independência).

\section{REFERÊNCIAS}

CARVALHO, Horácio Martins de. Formas de associativismo vivenciadas pelos trabalhadores rurais nas áreas oficiais de reforma agrária no
Brasil. Curitiba, Ministério Extraordinário de Política Fundiária e Instituto Interamericano de Cooperação para a Agricultura. Agosto, 1998. 
A Interação Social e as Possibilidades de Coesão e de Identidade Sociais no Cotidiano da Vida Social dos Trabalhadores Rurais nas Áreas Oficiais de Reforma Agrária no Brasil. Curitiba, 1999.

FABRINI, João Edmilson. 0 projeto do MST de desenvolvimento dos assentamentos e campesina territorial. Revista Terra Livre, ano 18, n. 19, p. 75-94 jul./dez., São Paulo, 2002.

FERNANDES, Bernardo Mançano. Movimento dos Trabalhadores Rurais Sem-Terra: formação e territorialização em São Paulo. $2^{\circ}$ ed, São Paulo: Hucitec, 1999.

FELICIANO, Carlos Alberto. Movimento camponês rebelde: a reforma agrária no Brasil. São Paulo: Contexto, 2006.

GOVERNA, Francesca. Sul ruolo attivo della territorialità di Francesca Governa, in DEMATTEIS, Giuseppe; GOVERNA, Francesca (a cura di). Territorialità sviluppo locale, sosteibilità: il modello slot, Franco Angeli, Milano, 2005.

LEITE, Sérgio. Impactos dos assentamentos: um estudo sobre o meio rural brasileiro. Brasília: Instituto Interamericano de Cooperação para a
Agricultura: Núcleo de Estudos Agrários e Desenvolvimento Rural; São Paulo: Ed. Unesp (coeditora e distribuidora), 2004. $391 \mathrm{p}$.

MAGNAGHI, Alberto. Il progetto locale: verso la coscienza di luogo, Bollati Boringhieri, Torino, 2010.

MARTINS, José de Souza. Reforma Agrária: o impossível diálogo. $1^{\circ}$ edição, $1^{\circ}$ reimpressão. São Paulo: Editora da Universidade de São Paulo, 2004.

MORAIS, Hugo Arruda de. Territórios, territorialidades e discursos em torno dos projetos de assentamentos rurais em Passira-PE: uma análise discursiva do processo de inclusão socioterritorial das famílias assentadas. Tese (doutorado), Universidade Federal de Pernambuco, CFCH, Programa de Pós-Graduação em Geografia, Recife, 2017.

RAFFESTIN, Claude. Por uma Geografia do poder. São Paulo: Editora Ática, 1993.

SANTOS, Milton. A Natureza do Espaço: técnica e

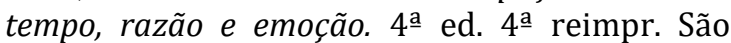
Paulo: Editora da Universidade de São Paulo, 2008. 